\title{
Formation and eruption of Sun-aligned arcs at the polar cap-auroral oval boundary
}

\author{
G. A. Berg, ${ }^{1}$ M. C. Kelley, ${ }^{2}$ M. Mendillo, ${ }^{3}$ R. Doe,${ }^{4}$ J. Vickrey,${ }^{4}$ C. Kletzing, ${ }^{5}$ \\ F. Primdahl, ${ }^{6}$ and K. D. Baker ${ }^{7}$
}

Abstract. This paper reports on results from a study of the poleward edge of the auroral oval in the morning sector using a comprehensive blend of in situ and ground-based measurements. Three rockets, equipped to measure electric and magnetic fields, energetic particles, and plasma density flew into an auroral display whose dynamical features were recorded with a digital image intensified all-sky camera as well as with an incoherent scatter radar. In addition, a number of DMSP satellite measurements bracketed the launch time. Evidence is presented here that in a condition of declining magnetic activity Sun-aligned arcs are injected into the polar cap at velocities $\sim 7 \mathrm{~km} / \mathrm{s}$ from locations of periodic brightening along the morningside of the auroral oval. The multipoint in situ measurements allow some separation of temporal and spatial effects and strongly suggest a poleward contraction of the convection pattern of about $0.25^{\circ}$ INVL in $70 \mathrm{~s}$. The most equatorward of the two brightest arcs studied erupted into a region which already was characterized by strong sunward convection. The most poleward, however, pushed into a region that had been convecting in an antisunward direction at velocities exceeding $1 \mathrm{~km} / \mathrm{s}$ less than $2 \mathrm{~min}$ earlier, and it is likely that sunward convection subsequently pertained poleward of that arc as well. We believe that these events mark the reconfiguration of the magnetosphere into a system characterized by a smaller polar cap.

\section{Introduction}

The National Aeronautics and Space Administration, in cooperation with the Air Force Geophysics Laboratory, the Danish Meteorological Institute (DMI), and the National Science Foundation conducted the Cooperative Observations of Polar Electrodynamics II (Cope II) sounding rocket campaign at the DMI's Sondre Stromfjord Rocket Range during February and March 1987. It was a follow-up to the COPE I Campaign carried out at the same site from January to March 1985.

The purpose of the project was to separate temporal and spatial factors in the polar cap ionosphere during times of polar cap aurora. Ideally, we would have had

\footnotetext{
${ }^{1}$ Center for Atmospheric and Space Sciences, Utah State University, Logan.

${ }^{2}$ School of Electrical Engineering, Cornell University, Ithaca, New York.

${ }^{3}$ Department of Astronomy, Boston University, Boston, Massachusetts.

${ }^{4}$ SRI International, Geoscience and Engineering Center, Menlo Park, California.

${ }^{5}$ Space Science Center, University of New Hampshire, Durham.

${ }^{6}$ Danish Space Research Institute, Lyngby, Denmark.

${ }^{7}$ Space Dynamics Laboratory, Utah State University, Logan.
}

Copyright 1994 by the American Geophysical Union.

Paper number 94JA01343.

0148-0227/94/94JA-01343\$05.00 access in real time to measurements of the interplanetary magnetic field (IMF), but this was not practical. Even requiring the existence of IMF data during the launch would have severely constrained our launch opportunities. Instead, we decided to rely on the imageintensified all-sky camera to reveal the state of the polar cap. The criterion was that patchy aurora be visible in the polar cap, and we envisioned that the most likely state of the system under these conditions would be the so-called I-type polar cap as defined by Heppner [1972]. As shall be seen below, we were fortunate indeed to intercept a much more organized auroral display as it evolved, providing observations of what we interpret to be the birth of two Sun-aligned arcs.

Such auroral displays have been reported for many years, and Akasofu [1985] reviews the associated physics and geophysics. This sort of aurora is mostly closely associated with a northward component of the IMF and a general quieting of worldwide magnetic activity. In the most extreme case of a strongly northward IMF, Sunaligned discrete arcs are distributed throughout the polar cap, and there is virtually no discernible auroral oval [Lassen and Danielsen, 1978]. In the other extreme of a strongly southward IMF the oval is well defined, and the polar cap is devoid of aurora. As reviewed by Akasofu, there is no fundamental difference between auroral oval and polar cap arcs; both are associated with upward field-aligned currents, have evidence for a parallel accelerating mechanism, and seem to be intimately related to the convection pattern. In fact, in terms of their importance for magnetospheric physics, one of the 
most crucial aspects is their relationship to the convection pattern and to questions about the region of open and closed field lines. It is well known that there is a distinct transition between the convection pattern in these two states of the magnetosphere. In this study we hope to show something about how this transition occurs and what role the Sun-aligned arcs play in it.

Much of our information on the polar cap has come from orbiting satellites and the Greenland chain of magnetometers and all-sky cameras. The former necessarily results in snapshots of the optical, particle, and field data as the spacecraft traverses the polar cap and gives no information on how the structures evolve in time. The latter is an enormous database and ill-suited to the study of individual events. In our case we used both in situ traversals of Sun-aligned arcs and all-sky images to study the relationship between the convection pattern, field-aligned currents, the auroral oval, and the evolution of Sun-aligned arcs in time during a quieting of the magnetospheric system.

As part of this campaign, three rockets were launched nearly simultaneously into the early-morning polar cap on trajectories which led them toward the auroral oval on March 31, 1987. These carried probes to measure electric and magnetic fields, electron density and temperature, and particle precipitation. From the ground the Sondre Stromfjord incoherent scatter radar measured similar fundamental plasma parameters, while an all-sky image-intensified digital camera imaged the $5577 \AA$ auroral emissions. Additionally, the DMSP satellites F6 and F7, while not orbiting near Sondre Stromfjord, provided valuable data concerning the large-scale dynamics of the polar cap and auroral oval; and IMP-J satellite flying beyond the magnetopause, measured the IMF and solar wind velocity. This combination of in situ and ground-based measurements represents the most complete array of instrumentation brought to date to a study of polar electrodynamics.

Elements of the geometry of the experiment are shown in Figure 1. The rockets flew from about $74^{\circ}$ to $70^{\circ}$ invariant latitude, corresponding to $L$ shells between about 13 and 8 . Two of the rockets, denoted Super 1 (38.010) and Super 2 (38.011), had threestage Taurus-Nike-Tomahawk motors, and they reached apogees of 467 and $441 \mathrm{~km}$, respectively. The other rocket, denoted Main (36.014) had a two-stage Black Brant IX motor and reached an apogee of $436 \mathrm{~km}$. Super 1 and Super 2 were launched 10 and $11 \mathrm{~s}$ after Main, respectively, which was launched at exactly 0447:00 UT. This corresponds to approximately 0310 magnetic local time (MLT). (The term "flight time" used in this paper refers to seconds or minutes and seconds after $0447 \mathrm{UT}$.)

The electric field instruments were of the doubleprobe variety with spherical electrodes mounted on the ends of insulating booms extending from the payload. The booms were quite long on the Main payload, having tip-to-tip electrode separations of $5.5 \mathrm{~m}$. Because of the smaller diameter of the Super payload, the tipto-tip distance was limited to $3 \mathrm{~m}$. High input resistance $\left(>10^{12} \Omega\right)$, low input capacitance $(<3 \mathrm{pF})$

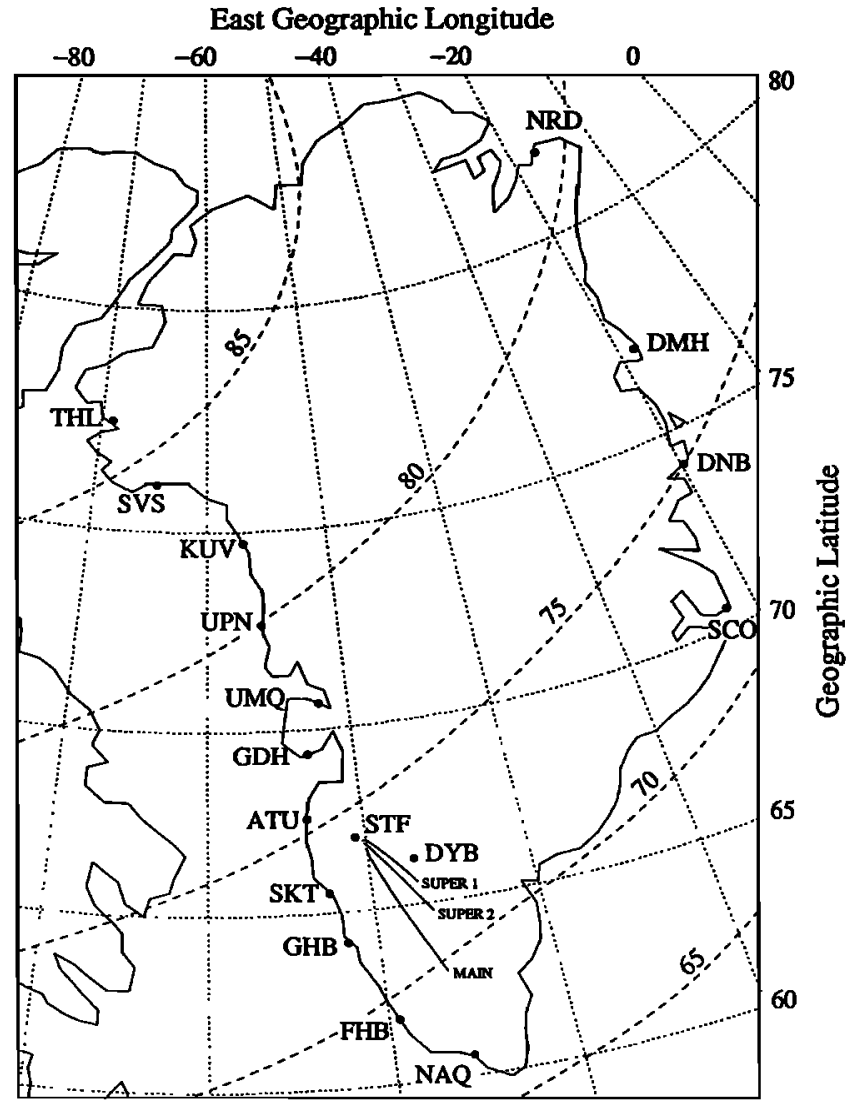

Figure 1. Map of Greenland showing the footprints (vehicle positions mapped along $B$ down to $150 \mathrm{~km}$ ) of the payload trajectories. Dotted lines mark the geographic grid, and dashed lines indicate constant invariant latitude circles. Solid circles mark the locations of the Greenland Magnetometer Chain stations.

preamps were used, allowing frequency response from dc to $5 \mathrm{MHz}$. The $\mathbf{V} \times \mathbf{B}$ field was subtracted using the known magnetic field strength, the rocket trajectory, and the vehicle attitude solution.

The Danish Space Research Institute provided a fluxgate magnetometer, which was carried by a daughter payload ejected from Main $68 \mathrm{~s}$ after launch. This was done to provide a clean environment, with as little contamination from payload currents as possible. The interesting physics is not contained in the total $\mathbf{B}$ measured, but in the fluctuations on top of the background geomagnetic field. Computing currents from these data requires knowing the orientation of the magnetometer with respect to the geomagnetic field at all times, and although the daughter payload carried no separate attitude system, a magnetometer provides its own attitude solution if spin and coning rates are constant and the initial conditions are known. Primdahl and Marklund [1986] discusses the method used in this study for determining the magnetic fluctuations $\delta B$ perpendicular to B. The daughter payload had constant spin and coning rates of 2.29 and $0.32 \mathrm{~Hz}$, respectively, indicating that the data reduction technique described by Primdahl and Marklund [1986] may be applied with confidence. Additionally, the dc-magnetometer outputs quieted down to 
the "least significant" of the 14 bits, indicating virtually no noise or interference.

Each of the payloads carried an electron and an ion detector. On the Main payload, this was a "top-hat" type electrostatic analyzer (ESA) which measured 16 pitch angles simultaneously and provided a full energy sweep from $20 \mathrm{eV}$ to $22 \mathrm{keV}$ in $42 \mathrm{~ms}$. On the two Super payloads, a combination ESA-retarding potential analyzer was flown which detected particles at seven pitch angles simultaneously and provided an energy sweep from $40 \mathrm{eV}$ to $2 \mathrm{keV}$ every $0.2 \mathrm{~s}$. The counts at each energy from all the detectors are linearly proportional to differential energy flux at this energy with a calibration that is expected to be accurate within $50 \%$. An underestimate of the differential energy flux is more likely than an overestimate because the microchannel plate counting efficiency has not been considered.

Supers 1 and 2 each carried a Utah State University plasma frequency probe (PFP), which locks on to the upper hybrid frequency $f_{\text {uh }}$, from which the absolute plasma density can be deduced [Berg, 1989; Swenson, 1989; Jensen and Baker, 1992]. This instrument only remains "locked on" to $f_{\mathrm{uh}}$ when the plasma frequency is somewhat larger than the gyrofrequency, putting a lower limit on the density which can be measured. Electron densities and line-of-sight velocities of the ionospheric plasma were measured by the Sondrestrom incoherent scatter radar (ISR).

The optical emissions from the $E$ layer aurora, filtered at $5577 \AA$, were recorded using an imageintensified digital all-sky camera provided by Boston University. Each image is a running average of 32 individual exposures which were each integrated for $667 \mathrm{~ms}$. Thus the period spanned by each image is approximately $20 \mathrm{~s}$. The digital counts at each pixel were converted to luminosity in kilorayleighs, where $1 \mathrm{R}=10^{6}$ photons $\mathrm{cm}^{-2} \mathrm{~s}^{-1}$. The conversion from counts to $\mathrm{kR}$ is estimated to be accurate within $50 \%$.

An overview of the rocket measurements on Main are provided in Figure 2 where the electron differential energy flux is plotted along with one electric field component and the orthogonal magnetic field component. As discussed in more detail elsewhere [Berg, 1993], the coordinate system was chosen to correspond to the symmetry associated with auroral arc elongation in a preferred direction. The all-sky images, as well as the field measurements, were used to define this arc coordinate system. The energy flux peaks at an energy just under $1 \mathrm{keV}$ which is consistent with the polar cap observations of Gussenhoven [1982] and Hardy et al. [1986]. The peak flux at $1 \mathrm{keV}$ is comparable with theta aurora and somewhat higher than typical subvisual arcs [Weber et al., 1989].

In a truly two-dimensional system of this type, $\delta E_{x}$ and $\delta B_{y}$ would be perfectly anticorrelated if $\Sigma_{P}$ were constant. Perusal of Figure 2 shows that, although not perfect, there is an evident anticorrelation. The initial plasma flow detected on the rocket was antisunward but reversed to sunward about $1^{\circ}$ equatorward of the launch site and remained that way the remainder of the flight. $A$ large inverted $V$ was crossed by the main payload as were several smaller ones. These major events, as well as the more frequent short bursts of precipitation, coincided with characteristic changes in $\delta \mathbf{E}$ and $\delta \mathbf{B}[B e r g$, 1993].

We concentrate here on what we consider to be the birth of two Sun-aligned arcs and the magnetospheric conditions under which they occurred. Details concerning the microscale features of the arcs will be published separately.

\section{Geophysical Conditions}

\subsection{IMF and Magnetic Activity Indices}

Geomagnetic activity was low when the three rockets Main, Super 1, and Super 2 were launched. For example, the 3-hour $K_{p}$ index for March 30 and 31, 1987, never exceeded 2-. The sum of the eight $K_{p}$ values for March 31 was 8 , making it the third most magnetically quiet day of the month. Additionally, the rockets flew near the beginning of a 3-hour period in which $K_{p}$ went from $2-$ to 1 , which suggests that the magnetic activity may have been going from low to very low during the flights.

The IMF data are also consistent with a quiet magnetosphere. Figure 3 presents the three components of the 15-s-averaged IMF for March 30 and 31,1987 measured by the IMP-J satellite flying well beyond the magnetopause at $30 R_{E}$. Allowing for a propagation time of the IMF signal of at least $11 \mathrm{~min}$ from IMP-J to the magnetopause, as calculated from the expression by Lester et al. [1993], the sounding rockets were launched at least 31 min prior to the end of a $2 \frac{1}{2}$-hour gap in the IMF data at the magnetopause. The reason for the data gaps is that no ground station was available to track IMP-J during those periods. Typical data coverage is about $65 \%$, so, although our luck was not perfect, we actually had better than average coverage (J. King, personal communication, 1991). Because of the data gap, we can only infer the long-timescale character of the IMF during the rocket flights. For timescales of the order of an hour, Figure 3 suggests that $B_{z}$ was between 0 and $-2 \mathrm{nT}$ and hence not northward. Since the topic of this paper is the formation of Sun-aligned arcs, we comment that although most closely associated with northward IMF, Sun-aligned arcs are observed in the polar cap for $B_{z}$ as negative as $-3 \mathrm{nT}$ [Gussenhoven, 1982]. For timescales less than an hour, Figure 3 tells us nothing about the sign of $B_{z}$ during the rocket flights. The highly variable nature of the data indicates that $B_{z}$ could very well have been positive. Such a short-timescale northward excursion of the IMF would be important if Sun-aligned arcs develop as quickly due to changes in the IMF as is suggested by the observations of Robinson et al. [1987].

The fact that $B_{y}$ was positive decreases the likelihood of observing aurora in the morning sector of the polar cap, which is where our observations were made [Lassen and Danielsen, 1978; Lassen, 1979; Ismail and Meng, 1982; Gussenhoven, 1982; Murphree et al., 1982]. However, with twice as many arcs occurring in the morning 


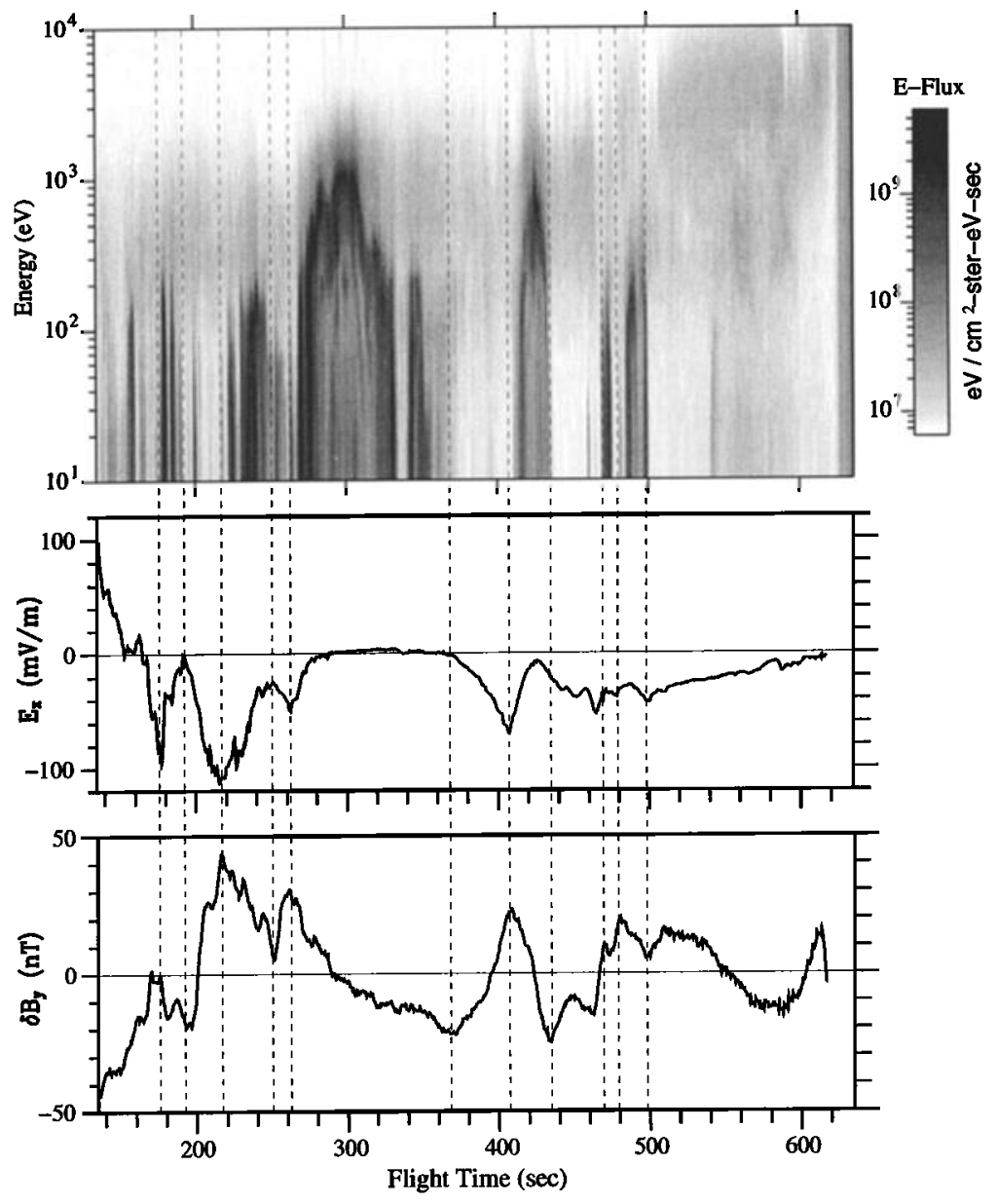

Figure 2. Electron precipitation and E-M fields observed by Main. The top panel shows the differential energy flux for pitch angles $\sim 0^{\circ}$. The center and bottom panels show $E_{x}$ and $\delta B_{y}$, respectively, in the arc coordinate system where the $x$ axis is perpendicular to the arc and the $y$ axis is parallel to it.

sector than in the evening sector, on average [Ismail et al., 1977; Lassen and Danielsen, 1978; Gussenhoven, 1982; Rairden and Mende, 1989], this tendency does not preclude our observing polar cap arcs. It is important to note that a tilting of the plasma sheet due to this IMF configuration would cause a poleward expansion of the evening edge of the oval, not the morning edge, which would rule out a tilted plasma sheet as the source for any arcs observed in the morning sector of the polar cap.

In addition to the IMF, IMP-J measured the velocity of the solar wind $V_{\mathrm{SW}}$, which also plays a factor in the energy budget at the magnetopause. During the data gap from 0230 to 0530 UT the hourly averaged solar wind speed dropped from 360 to $337 \mathrm{~km} / \mathrm{s}$, for an average decline of $7.67 \mathrm{~km} / \mathrm{s}$ per hour. On a longer timescale, between 0230 UT on March 30 and 2030 UT on March 31, the solar wind speed declined an average of $2.64 \mathrm{~km} / \mathrm{s}$ per hour. Hence the rockets flew during a period of general decline in $V_{\mathrm{SW}}$ with possibly a more rapid decline occurring during the flights. This is also consistent with a shrinking polar cap.

The most concrete evidence of a shrinking polar cap in connection with the rocket flights comes from the ge- omagnetic $A E$ index, which is known to be well correlated with IMF $B_{z}$ [Perreault and Akasofu, 1978]. Correlations performed between $A E$ and particle precipitation indicate that the amount of open magnetic flux increases or decreases depending on whether $A E$ increases or decreases [Akasofu, 1985]. In addition, Gussenhoven [1982] reported that Sun-aligned arcs are seen most frequently for low values $(<100 \gamma)$ of $A E$. Figure 4 gives the $A U, A L, A E$, and $A o$ indices for March 31, 1987, and shows that $A E$ was indeed decreasing, having a value conducive to the formation of Sun-aligned arcs, during the flight of the three rockets. If the observations of Ismail et al. [1977] are typical, namely that magnetic activity is higher before Sun-aligned arcs appear than after, then the fact that $A E$ was not only small but also decreasing during the flights is of prime importance.

\subsection{Polar Cap Particle Precipitation}

The electron precipitation measured by the DMSP F6 and F7 satellites as they flew across the northern polar cap and auroral zone are also consistent with a shrinking polar cap and show evidence of Sun-aligned arcs just before the rocket flights. First, the bound- 


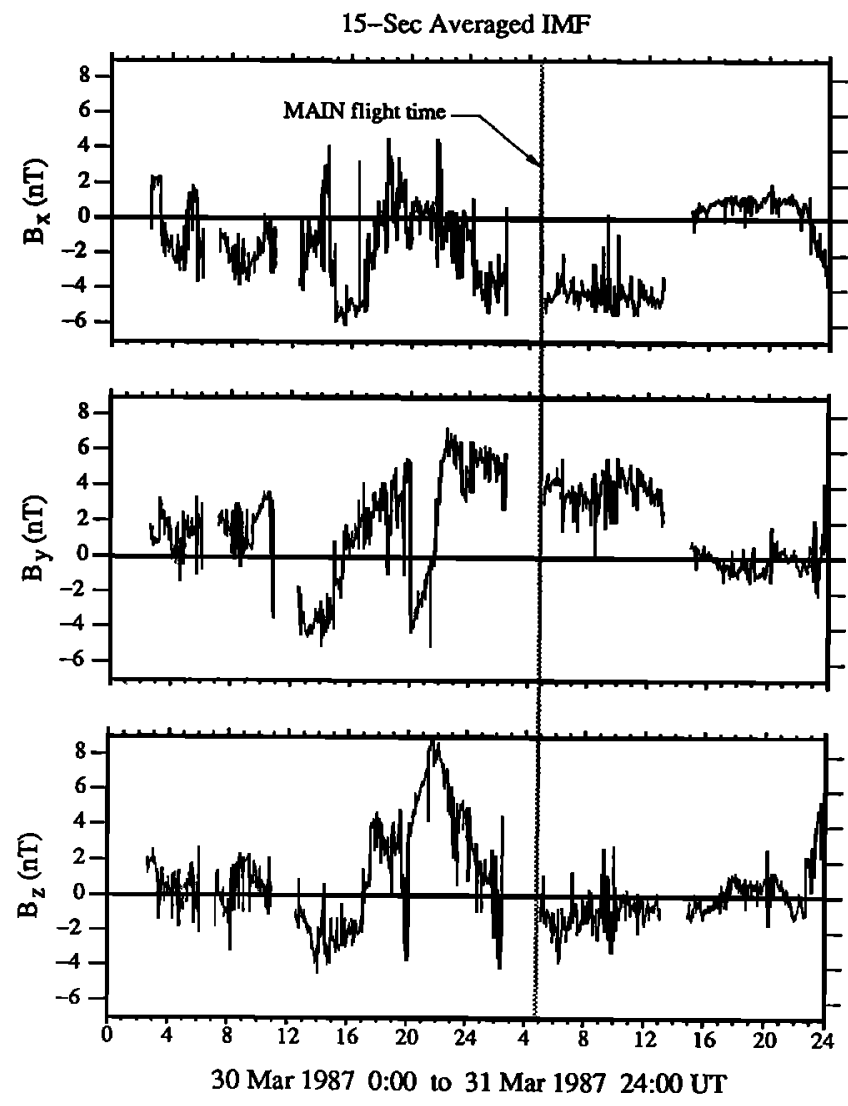

Figure 3. Fifteen-second averages of the components of the interplanetary magnetic field (IMF) as measured by the IMP-J satellite on March 30 and 31, 1987. The rockets in this study were flown during a data gap, corresponding to time intervals when the satellite was not being tracked.

aries of different types of electron precipitation suggest a small, and perhaps shrinking, polar cap. Newell et al. [1991] have developed an artificial intelligence program to analyze DMSP F7 electron data and deduce the magnetospheric source regions. Figure 5 presents a pictorial representation of the output of their program for the northern hemisphere for March 30 and 31, 1987. The different shaded regions were derived by connecting with straight lines, where possible, the boundaries of the deduced source regions from each polar pass, the time between each being $100 \mathrm{~min}$. For the F7 pass $22 \mathrm{~min}$ prior to the rocket flights (see the data point just before the straight line on the plot), the program deduced a poleward excursion of the nightside BPS boundary, suggestive of a smaller open field line region. The following pass, 100 min later, suggests that the BPS precipitation was receding equatorward.

An analysis of the particle data from individual DMSP satellite passes indicates that the morning of March 31,1987, was a time of considerable precipitation in the polar cap, particularly near the time of the rocket flights. Figure 6 shows how the total electron flux, rendered as a gray scale along appropriate satellite tracks, varied for all the $\mathrm{F} 6$ and $\mathrm{F} 7$ passes within about 2 hours of the rocket flights. It also gives the location of the passes with respect to the Feldstein and Starkov [1967] statistical oval, the field of view of the all-sky camera at Sondre Stromfjord, and the magnetic footprints of the three rockets. Enhanced electron precipitation was observed poleward of the statistical oval during each of the five satellite passes. However, polar showers, defined by Hardy et al. [1986] to be structured precipitation above $85^{\circ}$ INVL, were only observed during the $\mathrm{F} 6$ pass $43 \mathrm{~min}$ after the rocket launches. This was after the IMP-J data gap, and, allowing $11 \mathrm{~min}$ for the spacecraft-magnetopause time delay, IMF $B_{z} \approx 0$, verifying that a decisively positive $B_{z}$ is not a necessary condition for polar showers. Figure 6 suggests that the level of auroral activity in the polar cap increased significantly between $21 \mathrm{~min}$ prior to launch and $43 \mathrm{~min}$ after launch, which is near the end of the decline in the $A E$ index. By 80 min after launch the precipitation had receded equatorward again, consistent with evolution of the boundaries in Figure 5. These observations indicate that polar showers and hence Sun-aligned arcs may be more a signature of a declining level of geomagnetic activity than simply a low-level geomagnetic activity.

\subsection{All-Sky Camera Images}

Having discussed the conditions prevailing throughout the polar cap at the time of launch, we now turn to observations of the ionosphere above Sondre Stromfjord, Greenland, made just before and during the rocket flights. We begin with the all-sky camera images.

For the same horizontal displacement from an observer on the ground, an object at a low altitude will appear further from zenith than one at a high altitude,

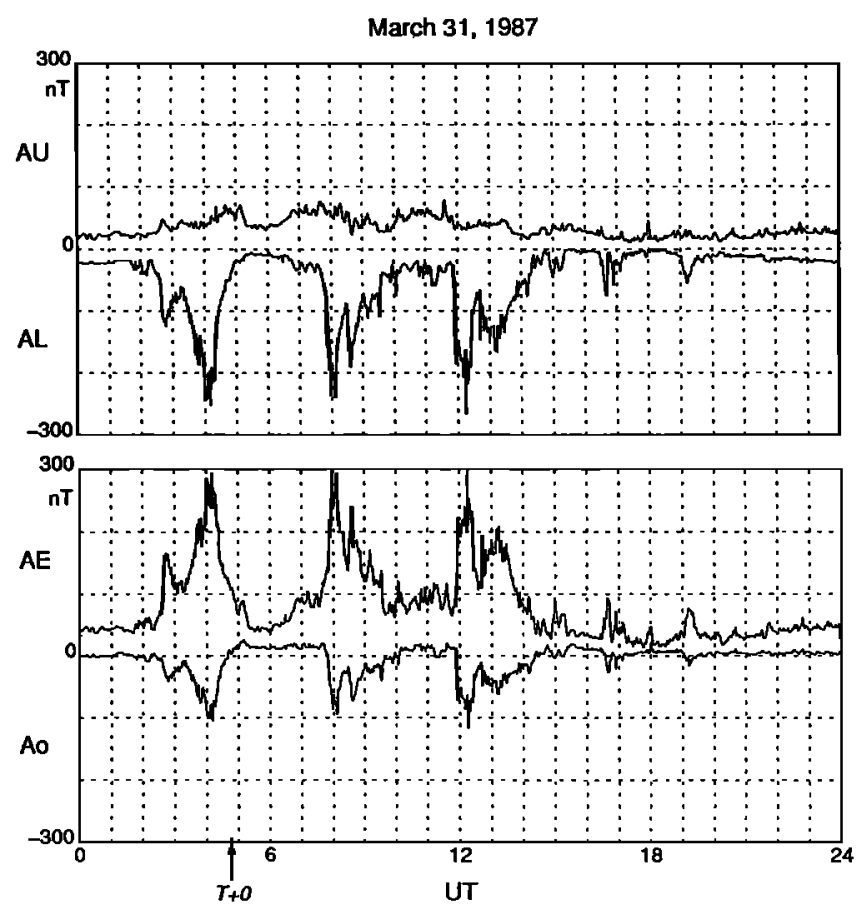

Figure 4. $A U, A L, A E$, and $A o$ magnetic indices for March 31, 1987, deduced from the superposition of twelve magnetograms. The arrow marks the time of launch $(T+0)$ for Main, Super 1, and Super 2. 


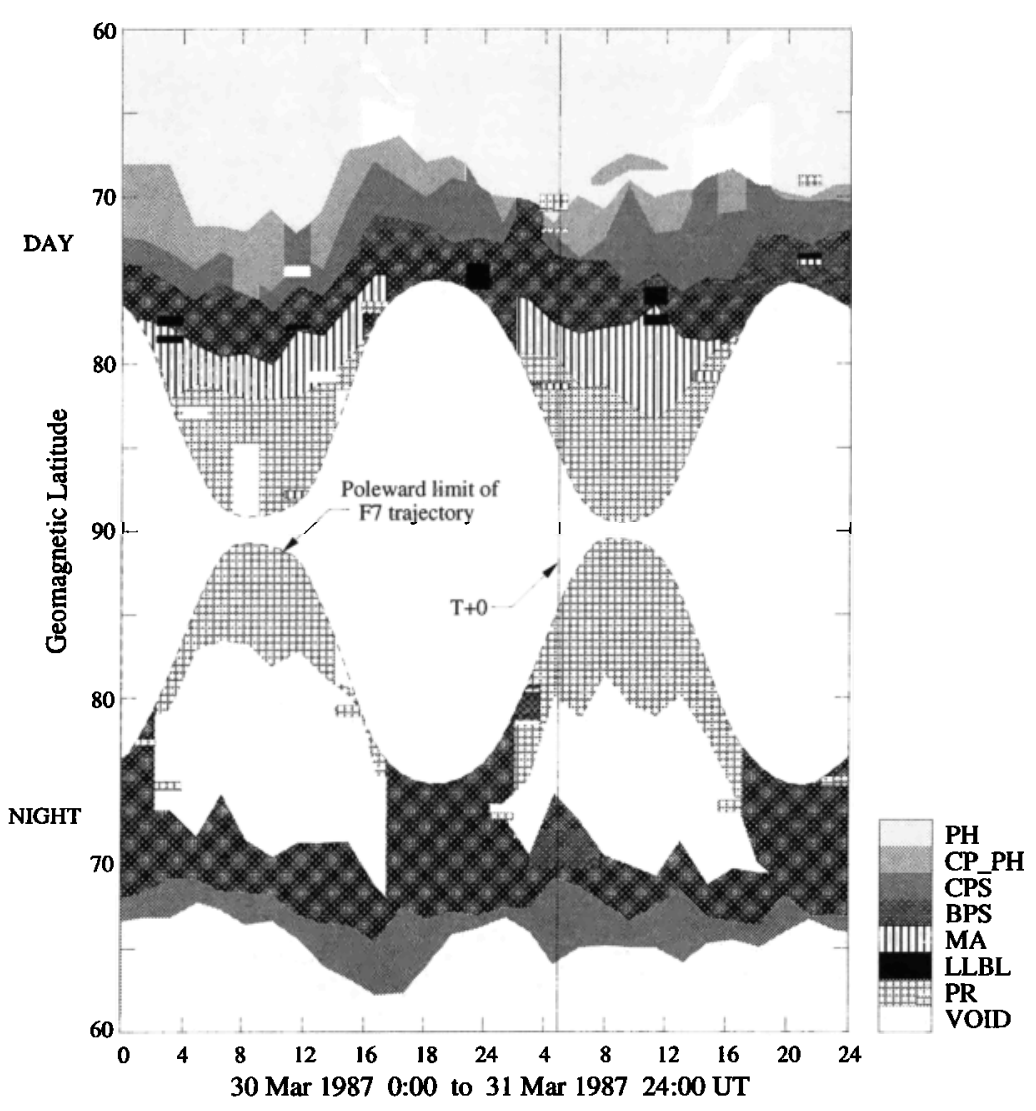

Figure 5. Source regions of particle precipitation in the northern hemisphere for March 30 and 31, 1987 deduced from DMSP F7 particle data by the neural network program of Newell et al. [1991]. Each pattern corresponds to particle precipitation characteristic of a particular source region. These are designated as VOID (no precipitation), PR (polar rain), LLBL (low-latitude boundary layer), MA (mantle), BPS (boundary plasma sheet), CPS (central plasma sheet), PH (photoelectrons), and CP_PH (CPS with photoelectrons).

such that the choice of a geographic grid depends highly on the assumed emission height.

Figure 7 gives profiles of the $5577 \AA$ emission rates deduced by using Main particle data at two times, one near the beginning, and the other in the center, of the inverted $\mathrm{V}$ shown in Figure 2, as inputs into the chemistry model used and discussed by Weber et al. [1989]. According to this model, precipitation in the center of the inverted $\mathrm{V}$ produced peak $5577 \AA$ emissions near $150 \mathrm{~km}$ altitude, while precipitation near the edge produced peak emissions near $190 \mathrm{~km}$. For a location of enhanced emissions in the images, believed to have been produced by this inverted- $V$ precipitation, emissions coming from these two altitudes would correspond to geodetic latitudes and longitudes of $\left(65.93^{\circ},-49.32^{\circ}\right)$ and $\left(65.66^{\circ},-48.92^{\circ}\right)$, respectively, a difference of $35 \mathrm{~km}$. An emission height of $170 \mathrm{~km}$ was chosen, based on the assumption that the enhanced emissions were indeed associated with the inverted $\mathrm{V}$, so that the center of the inverted $V$ would coincide in space and time with the center of the enhanced emissions. A transformation from pixel location to latitude and longitude can now be made, assuming that the $5577 \AA$ emissions originate at an altitude of $170 \mathrm{~km}$.

It should be evident from the above exercise that it is not possible, from all-sky camera images, to accurately determine the width of auroral forms away from zenith. As Figure 7 clearly shows, auroral emissions do not all come from the same altitude, and the variation of apparent horizontal displacement with mapping altitude also leads to ambiguity in the apparent width of the arc. This may account entirely for the discrepancy between the width of the "inverted V" $(30 \mathrm{~km})$ and the apparent optical width of a Sun-aligned arc $(90 \mathrm{~km})$ observed at $6300 \AA$ by Weber et al. [1989], which they explained by invoking the horizontal diffusion of $\mathrm{O}\left({ }^{1} D\right)$ theorized by Rees et al. [1967].

Since we are most interested in the arcs traversed by the rockets, we will use the $170 \mathrm{~km}$ transformation in all the images analyzed here. However, when used in discussions of the location of the auroral oval, it may well be that a lower height should have been used. This means that the poleward edge of the oval should be displaced closer to the camera (poleward). In Figure 8 we present two all-sky images taken closest to the flights, but before them. The $6300 \AA$ photo in Figure $8 \mathrm{a}$ was taken $12 \mathrm{~min}$ before launch and, as was the case for images taken for the previous 2 hours, shows the auroral oval but no evidence for Sun-aligned arcs. The $5577 \AA$ image in Figure $8 \mathrm{~b}$ was taken $1 \mathrm{~min}$ before launch and shows regions of brightening along the oval as well as localized regions of auroral light poleward of the oval. 


\section{DMSP Electron Flux}

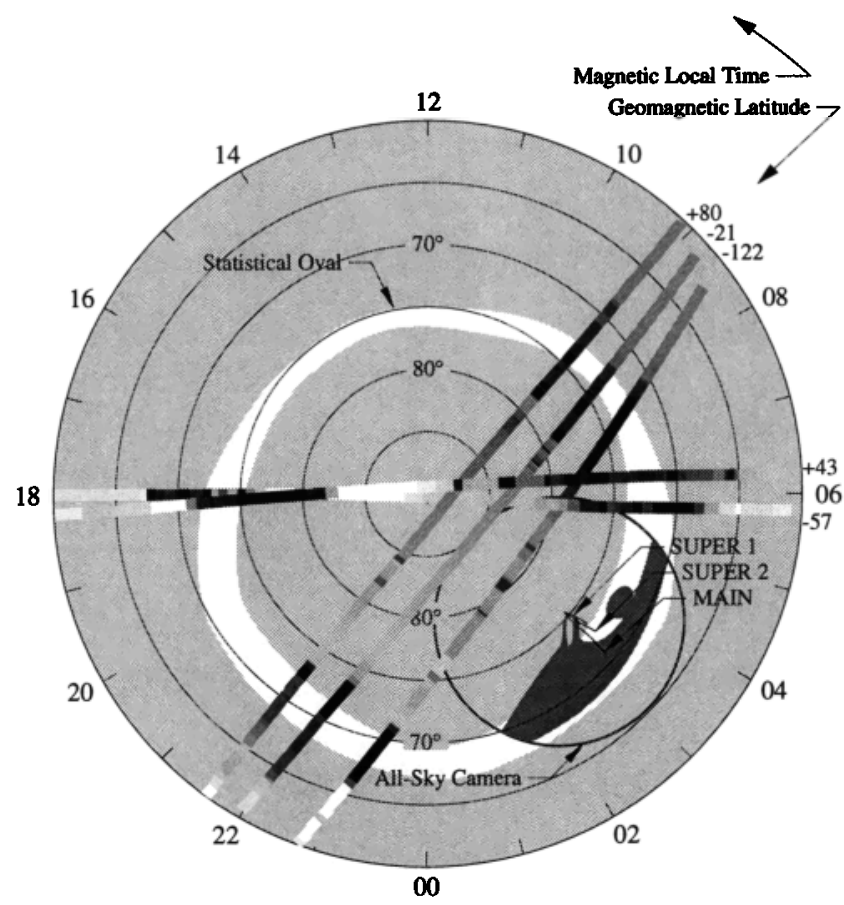

Figure 6. Gray scale representation of total electron flux measured by DMSP F6 and F7, where black denotes large flux, superimposed on the statistical oval of Feldstein and Starkov [1967] for magnetic index $Q=1$ (see King [1971] for a definition of $Q$ ). The number at the right of each satellite track is the time, in minutes, of the satellite pass relative to the launch time of Main $(T+0)$. The field of view of the all-sky camera depicts the region of enhanced $5577 \AA$ emissions at 0451:19 UT $(T+259 \mathrm{~s})$ and the footprints of the three rocket trajectories.

\section{Evolution of Two Sun-Aligned Arcs}

\subsection{All-sky images during the flights}

Figure 9a presents nine images captured by the allsky camera between 0450:06 (T+186 s) UT and 0453:03 $(T+363 \mathrm{~s}) \mathrm{UT}$, and Figure $9 \mathrm{~b}$ presents the subsequent nine images. Prior to this and subsequent to the images in Figure 8, the camera was using a lens with a narrow field of view, which proved to be a tactical mistake, in that high resolution overhead structures were less central to the results ultimately obtained. The three dots represent the positions of the three rockets projected down the magnetic field line to $170 \mathrm{~km}$.

These images indicate that two distinct auroral arcs emerged from the oval and crossed the footprints of the three rockets during flight. In this paper we will refer to the arc towards zenith (also poleward) as arc 1 and the other as arc 2. While arc 1 emerged after Main and Super 2 had passed, arc 2 emerged prior to their arrival; and, with good fortune, arc 2 was at its brightest during Main's traversal of it. It had dimmed considerably by the time Super 2 arrived and had faded entirely by the time Super 1 arrived. Although it looks like Super 1 may have flown through arc 1 , the particle data show no evidence of this. Just how we knew these arcs would emerge before the rockets were launched we leave to the realm of metaphysical thought. In retrospect, the existence of patchy aurora in the field of view, thought by the researchers to be evidence for the I-type irregular polar cap of Heppner [1972], may be a precursor for the more organized flow field and auroral features we actually traversed.

The visual characteristics of these arcs are consistent with those discussed in the literature of Sun-aligned arcs. First, they are approximately aligned with the Sun-Earth line. Ignoring the westward curve of its tip, arc 1 points about $18^{\circ}$ east of true north, while arc 2 points about $35^{\circ}$ east of true north. Using the auroral oval plotter of Whalen [1970], 1200 MLT is oriented about $25^{\circ}$ east of north at this location and time. Additionally, where the arcs merge with auroral oval, the oval brightens, a feature often associated with Sunaligned arcs [Frank et al., 1986; Gorney et al., 1986; Murphree et al., 1987].

For a more detailed examination of both the temporal and spatial structure of arc 2, Figure 10 shows how the center of the arc varied in space and time for the seven images recorded between 0450:30 and 0452:44 UT. Between 0450:30 and 0450:54 UT, the period of rapid emergence from the oval, the tip of the arc traveled approximately $100 \mathrm{~km}$, which corresponds to an average velocity of about $7 \mathrm{~km} / \mathrm{s}$. Additionally, the arc fluctuated significantly along its long dimension, appearing much like a flag flapping in the wind. Sunward (to the left) of the point where Main crossed the arc, the arc varied wildly in position between 0452:08 and 0452:44 UT, deviating transversely by as much as $30 \mathrm{~km}$. Since these images are accumulated over $18 \mathrm{~s}$, this represents an uncertainty in transverse location of the arc at any given time. Other than between 0451:43 and 0452:08 UT, curves 4 and 5, arc 2 appears to have been relatively stationary, in the transverse direction, at the point of crossing by Main (0451:55 \pm 20$)$. During that crucial period the arc apparently moved $11 \mathrm{~km}$ downrange, for an average apparent speed of $450 \mathrm{~m} / \mathrm{s}$.

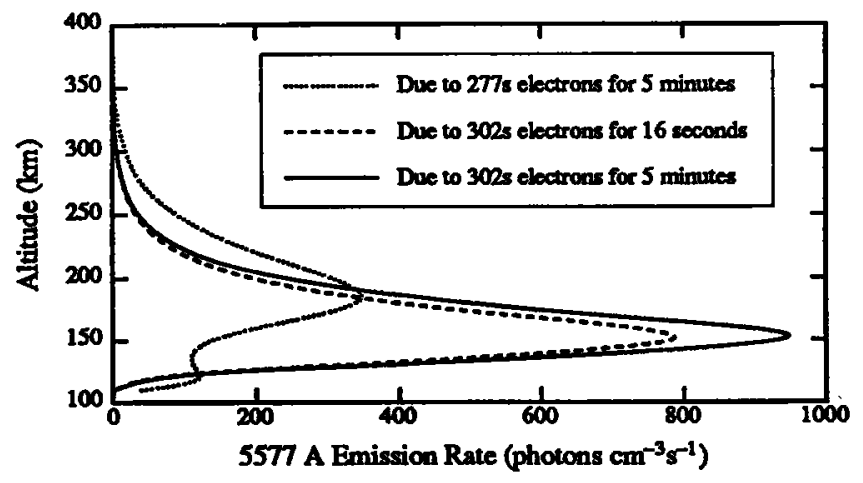

Figure 7. The $5577 \AA$ volume emission rate (photons $\mathrm{cm}^{-3} \mathrm{~s}^{-1}$ ) versus altitude assuming a sustained electron precipitation for the length of time indicated and as characterized by the particle data observed by Main at $277 \mathrm{~s}$ and $302 \mathrm{~s}$ flight time. For reference, the integrated intensity for the solid line is about $4 \mathrm{kR}$. 


\section{SONDRE STROMFJORD MARCH 31, 1987 PRE-LAUNCH IMAGES}

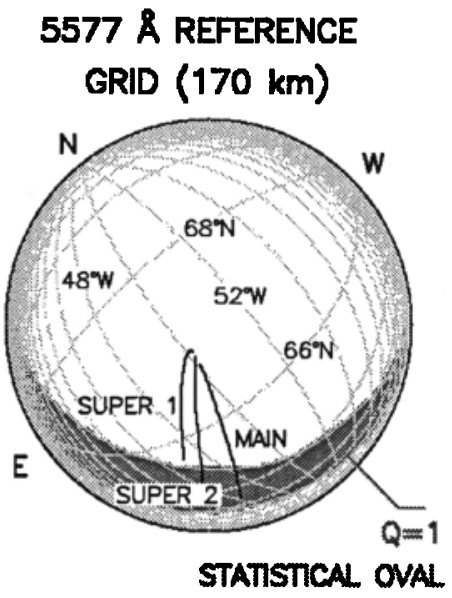

\section{BOSTON UNNERSITY IMAGING SYSTEM}
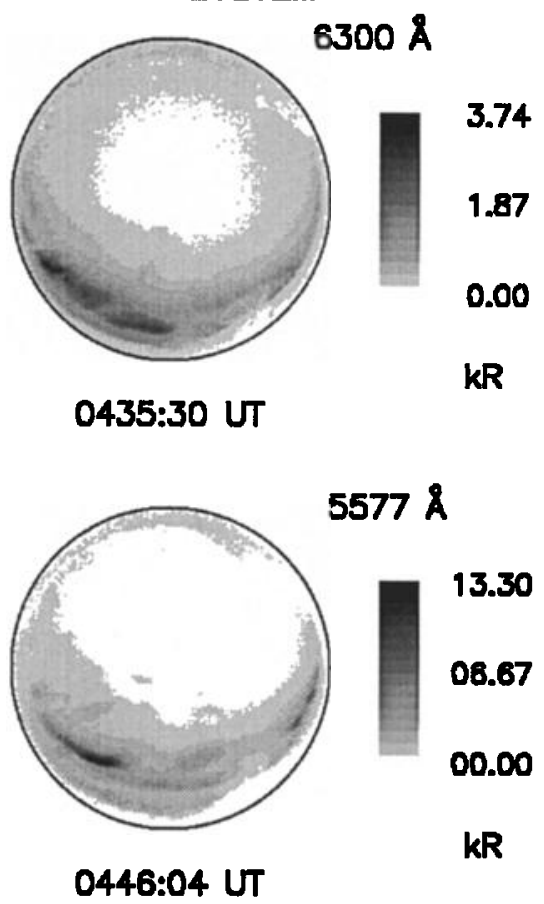

Figure 8. All-sky images closest in time but before the flight are presented in the top two panels. At the bottom, lines of constant latitude and longitude are plotted for the Boston University allsky camera, assuming that the $5577 \AA$ emissions came from $170 \mathrm{~km}$. Also shown are the magnetic footprints of Main, Super 1, and Super 2, and the $Q=1$ statistical oval of Feldstein and Starkov [1967].

BU IMAGING SYSTEM SONDRE STROMFJORD MARCH 31, 1987
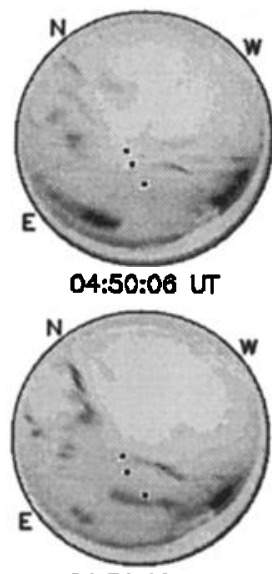

04:51:19 UT

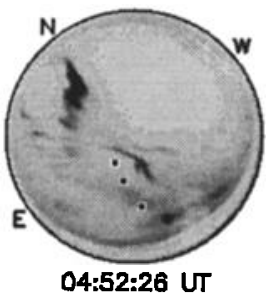

04:52:26 UT

\section{A IMAGES}
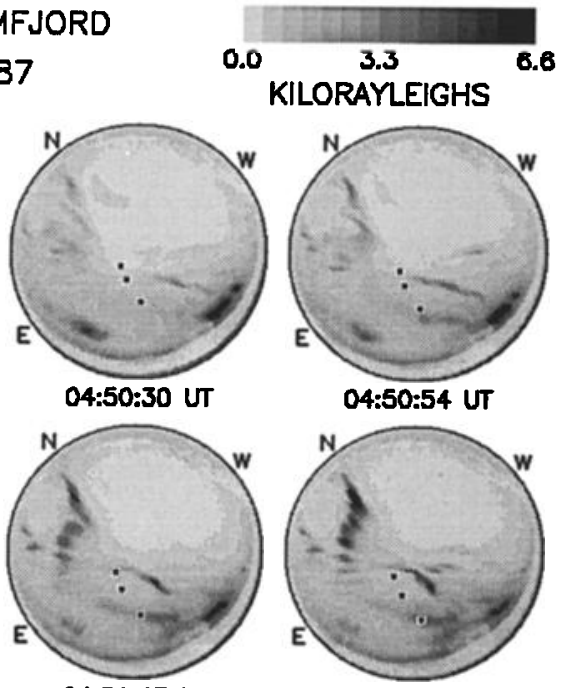

04:51:43 UT

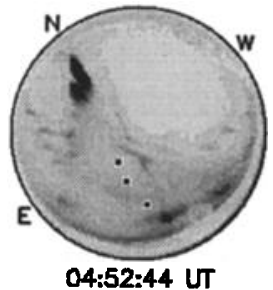

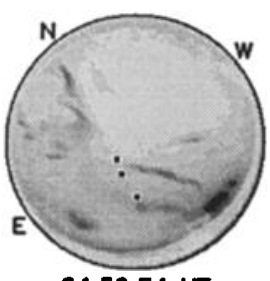

04:50:54 UT

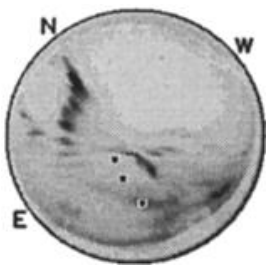

04:52:08 UT

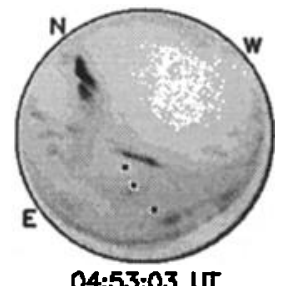

However, as in determining the width of the arc, this displacement could be entirely due to an increase in the average energy of the precipitating electrons, which would then deposit their energy at a lower altitude. The fact that the peak luminosity at the crossing went from 3.7 to $4.7 \mathrm{kR}$ between the two images is consistent with this explanation.

Although arc 2 was traversed by Main and Super 2, arc 1 is perhaps even more interesting. The latest images in Figure 9 show that, in contrast with arc 2, arc 1 persisted throughout the entire flight, fluctuating in brightness with a timescale of a minute or two. Additionally, the regions of greatest intensity travel along the length of the arc, moving sometimes toward the oval and other times toward the pole. While the arc shows little transverse motion early on, after 0452:26 UT it begins to drift dawnward at about $200 \mathrm{~m} / \mathrm{s}$ and continues to do so for the remainder of the flight. Taking into

Figure 9. (a) Images from the Boston University allsky camera between 0450:06 and 0453:03 UT on March 31,1987 , advancing in time from left to right and top to bottom. The black dots mark the footprints of the three rockets (Super 1, Super 2, and Main from near zenith outward), assuming an emission height $170 \mathrm{~km}$, at the time of each image. These images span flight times $T+186 \mathrm{~s}$ to $T+363 \mathrm{~s}$. 


\section{BU IMAGING SYSTEM} SONDRE STROMFJORD MARCH 31, 1987

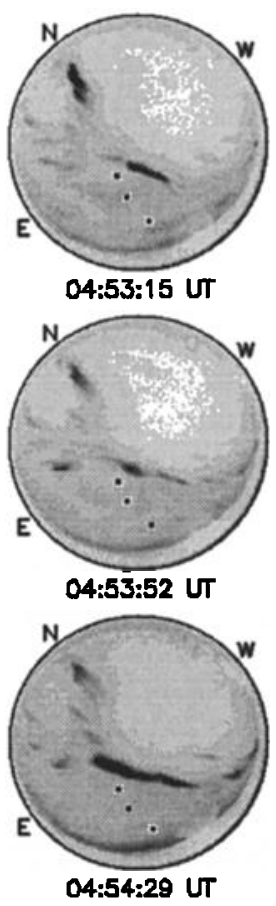

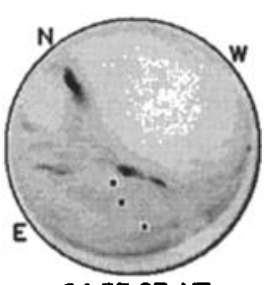

04:53:27 UT

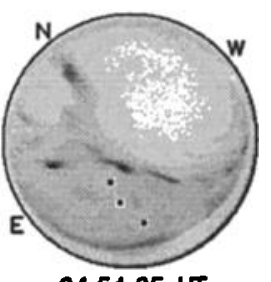

04:54:05 UT

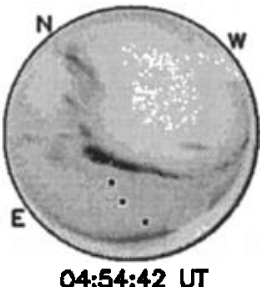

\section{A IMAGES}

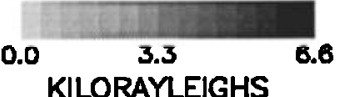

Figure 9. (b) Images from the Boston University allsky camera between 0453:15 and 0454:54 UT on March 31,1987 , covering flight times $T+375 \mathrm{~s}$ to $T+474 \mathrm{~s}$.

account the rotation of the Earth, this is nearly $400 \mathrm{~m} / \mathrm{s}$ in the Sun's reference frame. The optical data suggest that arc 1 remained the most poleward of the new arcs.

\subsection{Large-Scale Convection Patterns}

Narrowing our scope still further, we now concentrate on the electric field data measured by Main and Super 2. They imply that the overall convection pattern shifted poleward coincident with the emergence of the Sun-aligned arcs, a behavior that is consistent with the view that these arcs were associated with a shrinking polar cap. Figure 11a shows the meridional (magnetic north) and zonal (magnetic west) components of the electric field, in the Earth reference frame, deduced from the double-probe electric field data of Main. The data have been averaged to give approximately two samples per second. Figure $11 \mathrm{~b}$ shows the meridional and zonal components of the electric field in the Earth reference frame, deduced from the double-probe electric field data of Super 2. One of the booms snapped on Super 2 due to its unfortunately high spin rate, and a large coning resulted. The field was thus deduced using data from just one set of probes. It is thus possible that some of the fluctuations in Figure 11b, which are not seen in Figure 11a, particularly near the end of the flight, are due to errors in the data reduction process.

There is a clear similarity in the general features of the Main and Super 2 electric field data. The meridional and zonal components from both rockets reveal the same general trends, with Super 2 seeing the structures after Main, as would be expected due to the difference in their horizontal velocity. As will be discussed below, however, Main observed the structures at a lower invariant latitude than did Super 2. Where the Main and Super 2 E signatures are different, the differences make sense. Main observed larger fluctuations than Super 2, which was probably due to its closer proximity to the emerging arc 2 and the fact the arc had nearly died away by the time Super 2 reached it. Super 2 did see a larger southward electric field than Main, but this can be explained as a change in the overall large-scale convection pattern between the times that Main and Super 1 reached that region.

Figure 12 shows how the $V_{E \times B}$ (our notation for the $\mathbf{E} \times \mathbf{B}$ velocity) deduced from the Main electric field data varied along the rocket trajectory and its relation to observed features in the all-sky camera image at $T+283$ s, which was during the time that Main passed through arc 2. Initially, convection was approximately antisunward, but by the time Main encountered arc 2, the convection velocity had rotated to sunward. Within the arc, convection stagnated and then settled down into steady sunward flow downrange of the arc.

Figure 13 shows a similar picture for the convection velocities deduced from the Super 2 electric field data. In this case the image chosen as the backdrop corre-

\section{ARC 2 EVOLUTION}

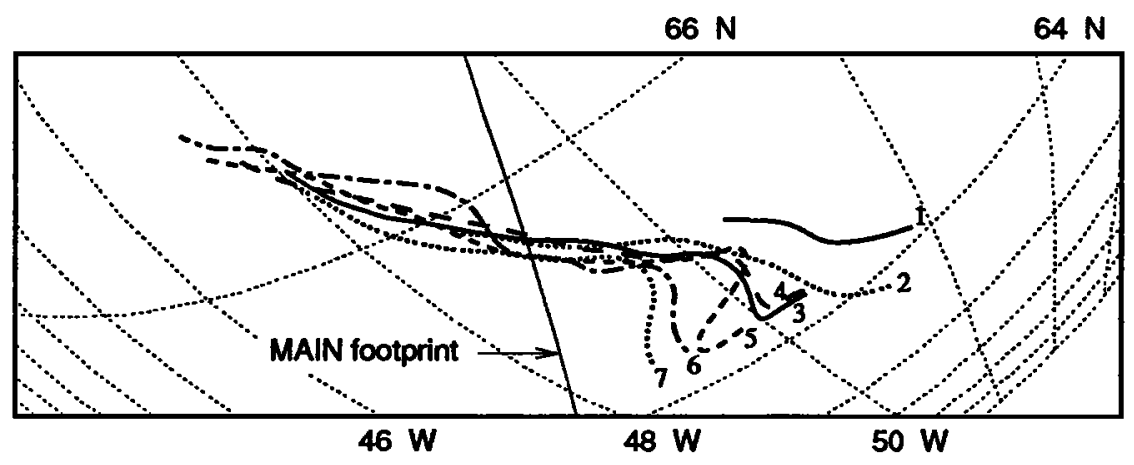

Figure 10. Curves of transverse maxima in $5577 \AA$ emissions along the length of the arc at (1) $0450: 30,(2) 0450: 54,(3) 0451: 19,(4) 0451: 43$, (5) 0452:08, (6) 0452:26, and (7) 0452:44 UT. 


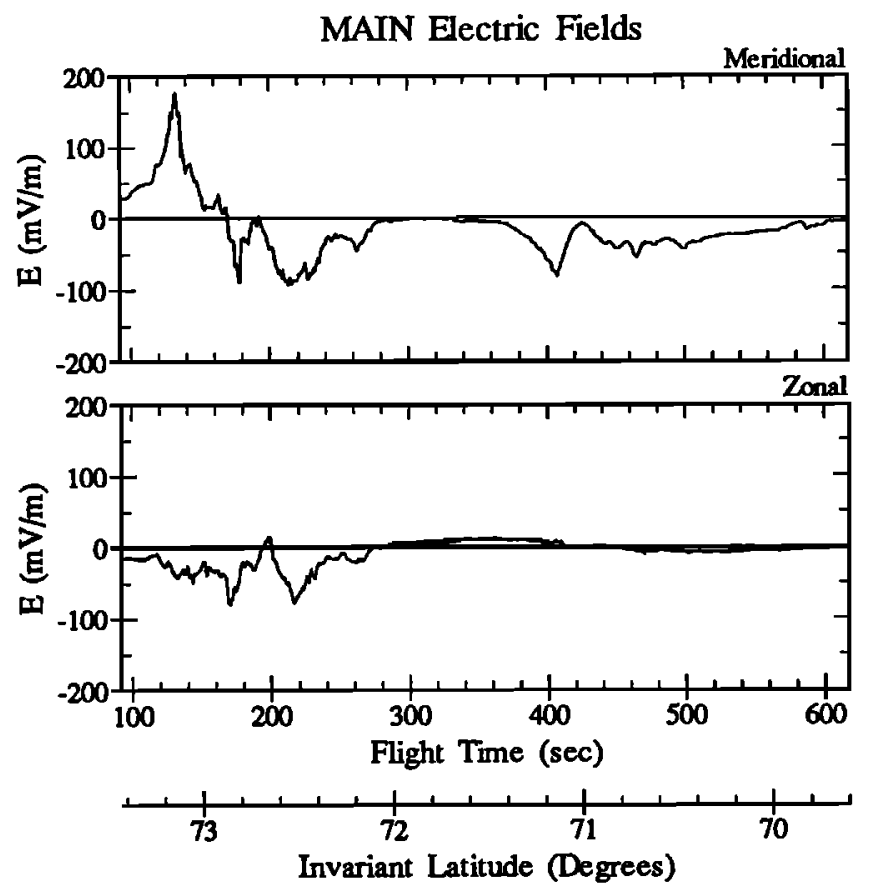

Figure 11. (a) Meridional and zonal electric fields versus flight time and invariant latitude in the Earth frame deduced from the data from two sets of double probes mounted perpendicularly on Main.

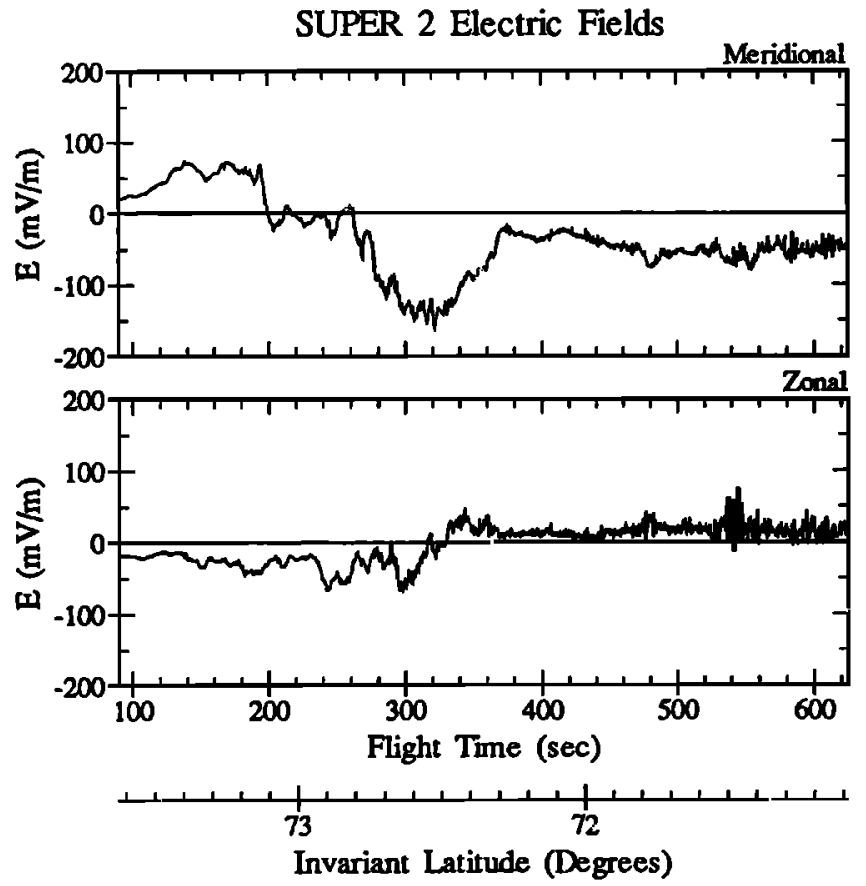

Figure 11. (b) Meridional and zonal electric fields versus flight time and invariant latitude in the Earth frame deduced from the data from one set of double probes on Super 2.

sponds to $T+375 \mathrm{~s}$, when Super 2 flew through the much weakened arc 2 . The general convection pattern is the same as for Main: antisunward, rotation to sunward, reduction of magnitude in the arc, and finally, steady sunward convection. This pattern, however, is shifted farther poleward in Figure 13 than Figure 12.
Consider, for example, the convection reversal observed between arc 1 and arc 2 . The convection velocity at Main rotated for the last time past due north at $T+191$ $s$ and an invariant latitude of $72.97^{\circ}$, whereas the convection velocity at Super 2 rotated for the last time past north at $T+262 \mathrm{~s}$ and an invariant latitude of $73.22^{\circ}$. This is a poleward shift of $0.25^{\circ}$ INVL in $71 \mathrm{~s}$, corresponding to an average poleward motion of $420 \mathrm{~m} / \mathrm{s}$.

Many consider the location of the large-scale convection reversal to coincide with the boundary between open and closed magnetic field lines [Akasofu, 1985, and references therein], and it is often used to define the polar cap boundary. If our observed reversal is indeed the large-scale convection reversal, this not only suggests that the polar cap decreased in size but also that the contraction occurred almost simultaneously with the eruption of arc 2 from the oval. At $T+191 \mathrm{~s}(19 \mathrm{~s}$ prior to curve 1 in Figure 10), arc 2 had not yet or was just beginning to emerge from the oval, and by $T+262$ (3 s after curve 3 in Figure 10), arc 2 had completed its rapid extension and was extending more slowly. Is it just a coincidence that Sun-aligned arcs formed during a contraction of the polar cap? We think not.

One might argue that the rotation of $\mathbf{E}$ measured by Main and Super 2 prior to passing through arc 2 was a temporal signature of the arcs extending toward the payloads rather than a strictly spatial structure corresponding to a convection reversal. However, there is little support for such a conclusion. Figure 14 shows

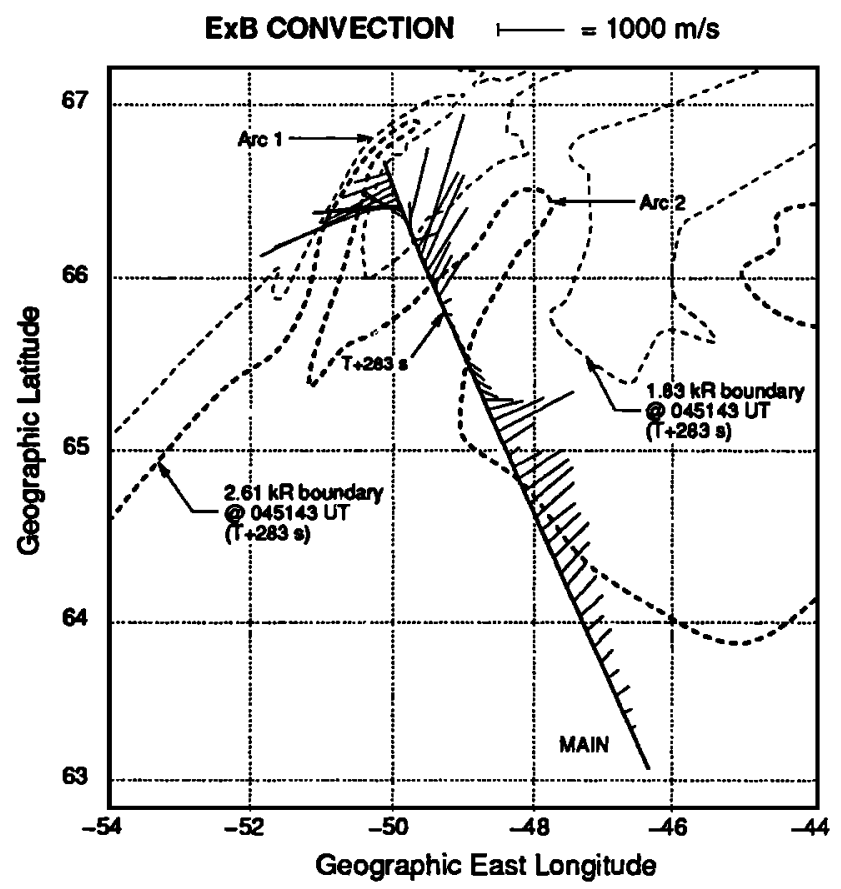

Figure 12. $\mathbf{E} \times \mathbf{B}$ drift velocities along the footprint of Main deduced from the double-probe electric field data. The length of the line is proportional to the magnitude of $\mathbf{V}_{\mathbf{E} \times \mathbf{B}}$ and its angle represents the direction. The temporal spacing between each velocity velocity vector is $10 \mathrm{~s}$. The heavy and light dashed lines denote the boundaries of 2.61 and $1.83 \mathrm{kR}$ luminosity at $5577 \AA$, respectively, at 0451:43 UT $(T+283 \mathrm{~s})$ in Figure 9a. An arrow marks the location of Main's footprint at that time. 


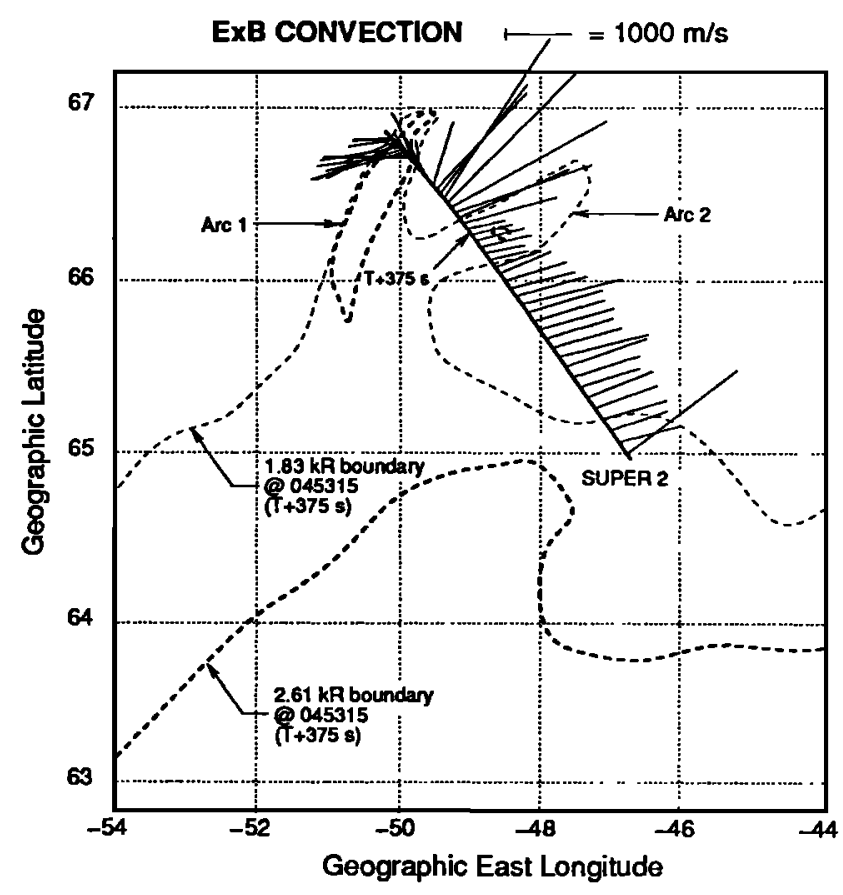

Figure 13. $\mathbf{E} \times \mathbf{B}$ drift velocities along the footprint of Super 2 deduced from the double-probe electric field data. The heavy and light dashed lines denote the boundaries of 2.61 and $1.83 \mathrm{kR}$ luminosity at $5577 \AA$, respectively, at 0453:15 UT $(T+375 \mathrm{~s})$ in Figure $9 \mathrm{~b}$. An arrow marks the location of the Super 2 footprint at that time.

the same convection velocities as in Figure 12, superimposed upon the all-sky camera image at $T+186 \mathrm{~s}$, which was the time of the first postlaunch image. By this time the convection velocity observed by Main had already rotated nearly sunward, although it was fluctuating somewhat. However, since arc 2 had not yet begun to emerge from the oval, this rotation cannot be attributed to its birth. The beginnings of arc 1 are present in this image, so perhaps the rotation was due to its initial emergence from the oval. A closer analysis, however, makes that also questionable. Both payloads observed a similar rotation, in which $\mathbf{V}_{\mathbf{E} \times \mathbf{B}}$ rotated from west of north to past or near north and then wobbled back and forth before turning permanently east of north and approximately sunward. However, the rotation began about $40 \mathrm{~s}$ earlier at Main than at Super 2, and, as noted above, permanent rotation past north occurred $71 \mathrm{~s}$ earlier at Main than at Super 2. Super 2 had not yet begun to observe a rotation in $\mathbf{V}_{\mathbf{E} \times \mathbf{B}}$ at the time of the first image. If the rotations were a temporal variation due to an emerging arc, one would expect both payloads to see at least some degree of rotation at roughly the same time. Hence the rotations are more a spatial variation than a temporal one, which indicates that the convection reversal was there prior to, but shifted poleward with, the appearance of the Sun-aligned arcs.

It deserves mention that in addition to their internal consistency, the rocket data agree with the lineof-sight velocities observed by the Sondre Stromfjord Radar [Berg, 1993]. For example, the line-of-sight drifts had a component directed toward the radar on the dusk (uprange) side of arc 2 and a component directed away from the radar on the dawn side of arc 2 .

\section{Conclusions}

We have studied in some detail the auroral features and convection patterns near the edge of the morning sector auroral oval when the $A E$ index was decreasing from a low value to virtually zero. Two Sun-aligned arcs were observed to emerge from the auroral oval and to jet across the night sky at speeds well in excess of the ionospheric $\mathbf{E} \times \mathbf{B}$ drifts detected in the region. The more equatorward of these arcs ( $\operatorname{arc} 2$ ) was traversed by both rockets and was characterized by a classic inverted $\mathrm{V}$ precipitation pattern with a peak energy flux of 2 ergs $\mathrm{cm}^{-2} \mathrm{~s}^{-1}$. The electron energy at the peak of the "V" was about $1 \mathrm{keV}$.

The rockets were launched inside the polar cap and each initially detected antisunward convection for several minutes. During this time the rockets moved about $1^{\circ}$ equatorward (magnetically). The optics show clearly that arc 2 erupted into a region shown by both rocket measurements to be convecting sunward at a high velocity before arc emergence. Super 2 observed the reversal from antisunward to sunward convection about $70 \mathrm{~s}$ later and $0.25^{\circ}$ INVL further poleward in invariant latitude than Main. This translates into an average poleward motion of the convection reversal of $420 \mathrm{~m} / \mathrm{s}$.

Arc 1 erupted into a region where the plasma had been convecting antisunward only $100 \mathrm{~s}$ earlier. It is likely that in the final state, when arc 1 delineated the poleward edge of the brightest aurora, sunward convec-

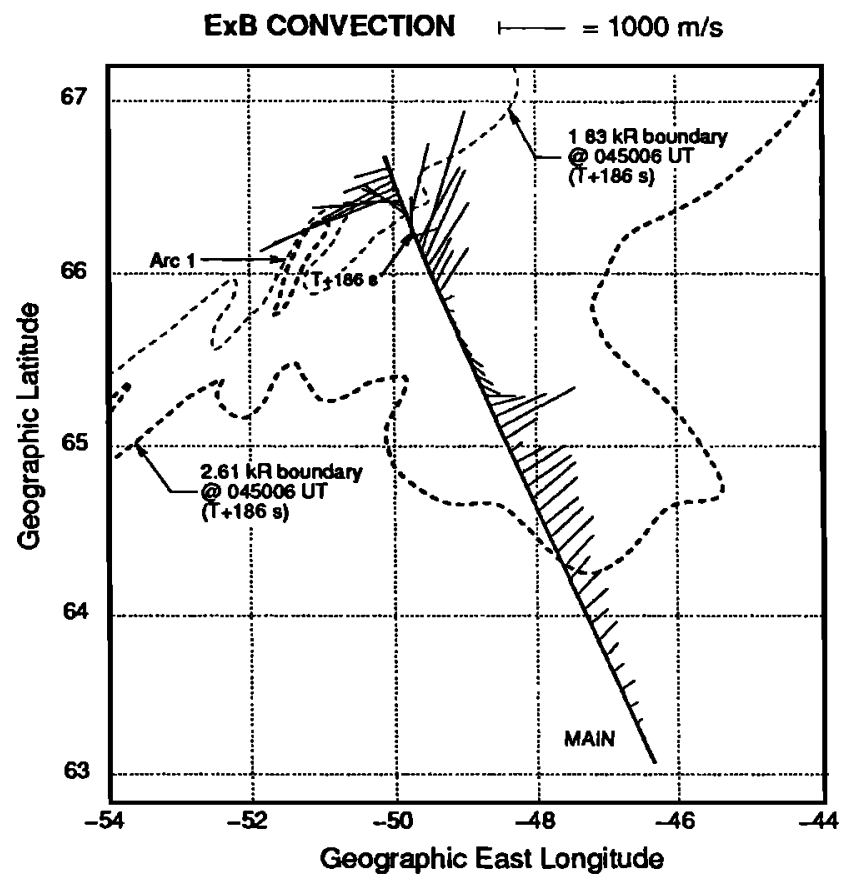

Figure 14. $\mathbf{E} \times \mathbf{B}$ drift velocities along the footprint of Main deduced from the double-probe electric field data. The heavy and light dashed lines denote the boundaries of 2.61 and $1.83 \mathrm{kR}$ luminosity at $5577 \AA$, respectively, at 0450:06 UT $(T+186 \mathrm{~s})$. An arrow marks the location of Main's footprint at that time. 
tion pertained at that location and poleward of it as well. That this would give $\boldsymbol{\nabla} \cdot \mathbf{E}<0$ inside arc 1 supports this view. This would suggest an even more rapid poleward motion of the polar cap boundary than that determined from the motion of the convection reversal between arc 1 and arc 2 .

The implication is that in a decaying magnetospheric condition, the flow field adjusts to a lower energy state and that this readjustment is accompanied by Sunaligned auroral arcs. The rocket-borne magnetic field measurements, which are necessarily limited to detecting current systems at scales $\leq 100 \mathrm{~km}$, showed 4-5 paired current sheets with roughly equal magnitude upward and downward Birkeland currents. One of these was at the instantaneous convection reversal boundary. Two of these paired sheets are clearly colocated with inverted V's detected by the particle detectors on board and one clearly with a Sun-aligned optical arc.

Finally, we speculate on the origin of the arcs. Both arc 1 and arc 2 erupted out of regions in the auroral oval which were brighter than the surrounding regions. If we identify areas of excess negative charge density with the precipitating electrons (as is consistent with the fact that the ionosphere is a net load on the magnetospheric generator and $\boldsymbol{\nabla} \cdot \mathbf{E}<0$ ) and the adjacent darker regions with excess positive charge density, then the paired current sheets might correspond to sunward advection and elongation of these regions from their initial location to their final position in the polar cap. The initial pattern of bright spots may be due to a mesoscale electrostatic instability, such as the Kelvin-Helmholtz, operating on the prior convection reversal boundary.

Acknowledgments. Research at Cornell University was conducted under NASA grant NSG-6020. Research by the group at the University of New Hampshire was supported under NASA grants NAG-656 and NAG-634 (at the University of Alabama in Hunstville). This work was supported at Boston University by NASA grant NAG5-640 and NSF grants ATM-9012786 and A'TM-9102557. We thank Poul Anker Jensen, currently at Southwest Research Institute, for contributing his expertise to the magnetometer construction on the Main payload. We also thank Robert Sheehan, at Boston College, for calculating $5577 \AA$ emission profiles from the Main particle data. We acknowledge the following for providing additional data: Dave Hardy, at Phillips Lab, and Cesar Valladares, at Boston College, for the DMSP data; Toyo Kamei, at the Data Analysis Center for Geomagnetism and Spacemagnetism in Kyoto, Japan, for the $A E$ indices; Ron Lepping, at the Goddard Space Flight Center, and the National Space Science Data Center for the IMP-J IMF data; and the CEDAR database for hourly averaged IMF and solar wind data and $K_{p}$ indices.

The Editor thanks R. A. Heelis and another referee for their assistance in evaluating this paper.

\section{References}

Akasofu, S.-I., The polar caps, in Energetics and Dynamics of the Middle and the Upper Atmosphere at High Southern Latitudes, National Institute of Polar Research, Tokyo, 1985.

Berg, G. A., Measurements and analysis of plasma density irregularities in the auroral ionosphere, Master's thesis, Utah State Univ., Logan, 1989.
Berg, G. A., Polar cap auroral arcs: Observations, theories, and a numerical model, Ph.D. thesis, Cornell Univ., Ithaca, NY, 1993.

Feldstein, Y. I., and G. V. Starkov, Dynamics of auroral belt and polar geomagnetic disturbances, Planet. Space Sci., $15,209,1967$.

Frank, L. A., J. D. Craven, D. A. Gurnett, S. D. Shawhan, D. R. Weimer, J. L. Burch, J. D. Winningham, C. R. Chappell, J. H. Waite, R. A. Heelis, N. C. Maynard, M. Sugiura, W. K. Peterson, and E. G. Shelley, The theta aurora, J.' Geophys. Res., 91, 3177, 1986.

Gorney, D. J., D. S. Evans, M. S. Gussenhoven, and P. F. M. Zera, A multiple-satellite observation of the high latitude auroral activity on January 11, 1983, J. Geophys. Res., 91, 339, 1986.

Gussenhoven, M. S., Extremely high latitude auroras, $J$. Geophys. Res., 87, 2401, 1982.

Hardy, D. A., M. S. Gussenhoven, K. Riehl, R. Burkhardt, N. Heinemann, and T. Schumaker, The characteristics of polar cap precipitation and their dependence on the interplanetary magnetic field, in Solar Wind-Magnetosphere Coupling, edited by Y. Kamide and J. A. Slavin, pp. 575604, Terra Scientific, Tokyo, 1986.

Heppner, J. P., Polar-cap electric field distributions related to the interplanetary magnetic field direction, J. Geophys. Res., 77, 4877, 1972.

Ismail, S., and C.-I. Meng, A classification of polar cap auroral arcs, Planet. Space Sci., 30, 319, 1982.

Ismail, S., D. D. Wallis, and L. L. Cogger, Characteristics of polar cap sun-earth aligned arcs, J. Geophys. Res., 82, 4741, 1977.

Jensen, M. D., and K. D. Baker, Measuring ionospheric electron-density using the plasma frequency probe, $J$. Spacecraft Rockets, 29, 91-95, 1992.

King, J. H. Ed., Handbook of Correlative Data, National Space Science Data Center, Greenbelt, Md., 1971.

Lassen, K., The quiet-time pattern of auroral arcs as a consequence of magnetospheric convection, Pap. $R-56$, Dan. Meteorol. Inst., Copenhagen, 1979.

Lassen, K., and C. Danielsen, Quiet-time patterns of auroral arcs for different directions of interplanetary magnetic field in the $y-z$ plane, J. Geophys. Res., 83, 5277, 1978.

Lester, M., O. de la Beaujardiére, J. C. Foster, M. P. Freeman, H. Lühr, J. M. Ruohoniemi, and W. Swider, The response of the large scale ionospheric convection pattern to changes in the IMF and substormse: Results from the SUNDIAL 1987 campaign, Annal. Geophys., 11, 556-571, 1993.

Murphree, J. S., C. D. Anger, and L. L. Cogger, The instantaneous relationship between polar cap and oval auroras at times of northward interplanetary magnetic field, Can. J. Phys., 60, 349, 1982.

Murphree, J. S., L. L. Cogger, C. D. Anger, D. D. Wallis, and G. G. Shepherd, Oval intensification associated with polar arcs, Geophys. Res. Lett., 14, 403, 1987.

Newell, P. T., S. Wing, C. Meng, and V. Sigillito, The auroral oval position, structure, and intensity of precipitation from 1984 onward: An automated on-line data base, $J$. Geophys. Res., 96, 5877, 1991.

Perreault, P., and S.-I. Akasofu, A study of geomagnetic storms, Geophys. J. R. Astron. Soc., 54, 547, 1978.

Primdahl, F., and G. Marklund, Birkeland currents correlated with direct-current electric fields observed during the CENTAUR Black Brant X rocket experiment, Can. J. Phys., 64, 1412-1416, 1986.

Rairden, R. L., and S. B. Mende, Properties of $6300-\AA$ auroral emissions at the south pole, J. Geophys. Res., 94, $1402,1989$.

Rees, M. H., J. C. G. Walker, and A. Dalgarno, Auroral 
excitation of the forbidden lines of atomic oxygen, Planet. Space Sci., 15, 1097, 1967.

Robinson, R. M., R. R. Vondrak, and E. Friis-Christensen, Ionospheric currents associated with a sun-aligned arc connected to the auroral oval, Geophys. Res. Lett., 14, $656,1987$.

Swenson, C. M., An evaluation of the plasma frequency probe, Master's thesis, Utah State Univ., Logan, 1989.

Weber, E. J., M. C. Kelley, J. O. Ballenthin, S. Basu, H. C. Carlson, J. R. Fleischman, D. A. Hardy, N. C. Maynard, R. F. Pfaff, P. Rodriguez, R. E. Sheehan, and M. Smiddy, Rocket measurements within a polar cap arc: Plasma, particle, and electric circuit parameters, J. Geophys. Res., 94, 6692, 1989.

Whalen, J. A., Auroral oval plotter and nomograph for determining corrected geomagnetic local time, latitude, and longitude for ligh latitudes in the northern hemisphere, Rep. AFCRL-70-0422, Air Force Cambridge Res. Lab., Bedford, Mass., 1970.

K. D. Baker, Space Dynamics Laboratory, Utah State
University, Logan, UT 84322-4120 (e-mail: kbaker@usu. ediI).

G. A. Berg, Center for Atmospheric and Space Scicnces, Utah State University, Logan, UT 84322-4405 (e-mail: berg@usu.edu).

R. Doe and J. Vickrey, SRI International, Geoscience and Engineering Center, Menlo Park, CA 94025 (e-mail: doc@spica.bu.edu; vickrey@sri.com).

M. C. Kelley, School of Electrical Engineering, Cornell University, Ithaca, NY 14850 (e-mail: mikek@magneto.ee. cornell.edu).

C. Kletzing, Space Science Center/SERB, University of New Ilampshire, Durham, NH 03824 (e-mail: kletzing@ unhesp.unh.edu).

M. Mendillo, Department of Astronomy, Boston University, Boston, MA 02215 (e-mail: mendillo@buasta.bu.edu).

F. Primdahl, Danish Space Research Institute, Lynghy, Denmark (e-mail: driprim@vm.uni-c.dk).

(Received June 11, 1993; revised May 11, 1994; accepted May 17, 1994.) 